\title{
Improving the Quality of Primary Care by Optimizing Implementation Research Reporting
}

\author{
Gonzalo Grandes, MD, MS, Hilary Pinnock, MD, Andrew Bazemore, MD, MPH, \\ Paul Meissner, MSPH, and The StaRI Group
}

The potential of implementation research in understanding strategies for changing practice is undermined by poor reporting, leaving readers unable to replicate such strategies and unclear whether they apply in the context of their practice. These challenges are particularly pertinent in the complex, diverse world of primary care. The recently published Standards for Reporting Implementation Studies (StaRI) provides a framework for comprehensive reporting of implementation research. A key concept is the consideration and reporting in "dual strands": on the one hand, the implementation strategy and on the other, the evidence-based intervention. Other requirements are full descriptions of context, strategies and interventions (and how the strategies were adopted or adapted), and evaluation methods, which will require flexible interpretation of journal limit constraints or innovative approaches to supplementary information. The choice is between accepting the unsatisfactory status quo or adopting strategies to improve reporting with a view to optimizing the potential of implementation research to advance primary care. (J Am Board Fam Med 2018;31:484-487.)

Keywords: Implementation Science, Primary Health Care

The need to understand the factors determining successful uptake of innovation in primary care settings, where there are a myriad of evidencebased preventive, diagnostic, and management interventions from which to select, is well recognized. ${ }^{1}$ Yet, there is still substantial incongruence between recommendations and actual practice. ${ }^{2-4}$ How can proven procedures be applied in a systematic and sustainable way to all patients likely to benefit from them, without losing effectiveness?

This article was externally peer reviewed.

Submitted 11 May 2017; revised 10 September 2017; accepted 20 October 2017.

From Primary Care Research Unit of Bizkaia at the Basque Healthcare Service, Primary Health Care Research at the BioCruces Research Institute; Bilbao, Spain (GG); Primary Care Respiratory Medicine, Allergy and Respiratory Research Group, Usher Institute for Population Health Sciences and Informatics, The University of Edinburgh, Scotland, UK (HP); The Robert Graham Center; Washington, DC, USA (AB); Montefiore Medical Center, The University Hospital for Albert Einstein College of Medicine, Bronx, NY, USA (PM)

Funding: none.

Conflict of interest: none declared.

Corresponding author: Gonzalo Grandes, MD, MS, Unidad de Investigación en Atención Primaria, Ambulatorio de Deusto, Osakidetza, Luis Power 18, planta 4, E-48014 Bilbao, Spain (E-mail: gonzalo.grandes@osakidetza.eus).
This is the question which the scientific methodologies of implementation research attempt to answer, shifting the focus from the "what" (evidencebased intervention to use) to the "how" (to adopt recommended care in routine primary care practice). ${ }^{5}$ The gap between what is actually done and what should be done exists across all health care sectors, but it is especially challenging in primary care, due to its inherent complexity and breadth. ${ }^{6}$ We know some of the challenges: implementing the "hundreds" of specialist clinical guidelines disseminated to primary care, working with limited resources, and the gap between the demands of implementation and the limited capacity of busy frontline medicine, which stifles change. ${ }^{7}$ Understanding implementation strategies and evaluating the effectiveness of evidence-based interventions when they are delivered in routine practice to unrestricted general populations in the context of typical community practice, are the remit of implementation research. "Real world laboratories," such as the practice-based research networks and primary care centers, are crucial to this science. ${ }^{8,9}$

Although implementation research has contributed over the past 15 years to our understanding of 
Table 1. The Checklist for Standards for Reporting Implementation Studies*

\begin{tabular}{|c|c|c|c|}
\hline $\begin{array}{l}\text { Report t } \\
\text { Followin }\end{array}$ & & $\begin{array}{l}\text { "Implementation strategy" refers to how the int } \\
\text { the healthcare or public health in }\end{array}$ & $\begin{array}{l}\text { ntion was implemented. "Intervention" refers to } \\
\text { ention that is being implemented. }\end{array}$ \\
\hline Checklist & & Implementation Strategy & Intervention \\
\hline Title & 1 & $\begin{array}{l}\text { Identification as an implementation study, and } \mathrm{d} \\
\text { keywords. }\end{array}$ & iption of the methodology in the title and/or \\
\hline Abstract & 2 & $\begin{array}{l}\text { Identification as an implementation study, incluc } \\
\text { be tested, the evidence-based intervention bei } \\
\text { implementation and health outcomes. }\end{array}$ & $\begin{array}{l}\text { a description of the implementation strategy to } \\
\text { nplemented, and defining the key }\end{array}$ \\
\hline Introduction & 3 & $\begin{array}{l}\text { Description of the deficiency in healthcare or pu } \\
\text { aims to address. }\end{array}$ & health that the intervention being implemented \\
\hline & 4 & $\begin{array}{l}\text { The scientific background and rationale for the } \\
\text { implementation strategy (including any } \\
\text { underpinning theory/framework/model, how } \\
\text { it is expected to achieve its effects, and any } \\
\text { pilot work). }\end{array}$ & $\begin{array}{l}\text { The scientific background and rationale for the } \\
\text { intervention being implemented (including } \\
\text { evidence about its effectiveness and how it is } \\
\text { expected to achieve its effects). }\end{array}$ \\
\hline $\begin{array}{l}\text { Aims and } \\
\text { objectives }\end{array}$ & 5 & $\begin{array}{l}\text { The aims of the study, differentiating between in } \\
\text { objectives. }\end{array}$ & mentation objectives and any intervention \\
\hline $\begin{array}{l}\text { Methods: } \\
\text { description }\end{array}$ & 6 & $\begin{array}{l}\text { The design and key features of the evaluation, ( } \\
\text { reporting standards) and any changes to study }\end{array}$ & $\begin{array}{l}\text { referencing to any appropriate methodology } \\
\text { tocol, with reasons. }\end{array}$ \\
\hline & 7 & $\begin{array}{l}\text { The context in which the intervention was imple } \\
\text { healthcare, organizational barriers, and facilita } \\
\text { elsewhere). }\end{array}$ & $\begin{array}{l}\text { ted (considered social, economic, policy, } \\
\text { that might influence implementation }\end{array}$ \\
\hline & 8 & $\begin{array}{l}\text { The characteristics of the targeted "site(s)" } \\
\text { (eg, locations, personnel, and resources) } \\
\text { for implementation and any eligibility } \\
\text { criteria. }\end{array}$ & $\begin{array}{l}\text { The population targeted by the intervention } \\
\text { and any eligibility criteria. }\end{array}$ \\
\hline & 9 & A description of the implementation strategy. & A description of the intervention. \\
\hline & 10 & Any subgroups recruited for additional research & $s$ and/or nested studies are described. \\
\hline $\begin{array}{l}\text { Methods: } \\
\text { evaluation }\end{array}$ & 11 & $\begin{array}{l}\text { Defined prespecified primary and other } \\
\text { outcome(s) of the implementation strategy } \\
\text { and how they were assessed. Document any } \\
\text { predetermined targets. }\end{array}$ & $\begin{array}{l}\text { Defined prespecified primary and other } \\
\text { outcome(s) of the intervention (if assessed) } \\
\text { and how they were assessed. Document any } \\
\text { predetermined targets. }\end{array}$ \\
\hline & 12 & Process evaluation aims and outcomes related ba & o the "logic pathway." \\
\hline & 13 & $\begin{array}{l}\text { Methods for resource use, costs, outcomes, and } \\
\text { analysis for the implementation strategy. }\end{array}$ & $\begin{array}{l}\text { Methods for resource use, costs, outcomes, and } \\
\text { analysis for the intervention. }\end{array}$ \\
\hline & 14 & $\begin{array}{l}\text { Rationale for sample sizes (including sample size } \\
\text { considerations, and data saturation, as approp }\end{array}$ & culations, budgetary constraints, practical \\
\hline & 15 & Methods of analysis (with reasons for that choice & \\
\hline & 16 & $\begin{array}{l}\text { Any a priori subgroup analyses (eg, between } \mathrm{d} \\
\text { clinical or demographic populations), and su } \\
\text { tasks. }\end{array}$ & $\begin{array}{l}\text { ent sites in a multicenter study, and different } \\
\text { oups recruited to specific nested research }\end{array}$ \\
\hline Results & 17 & $\begin{array}{l}\text { Proportion recruited and characteristics of the } \\
\text { recipient population for the implementation } \\
\text { strategy. }\end{array}$ & $\begin{array}{l}\text { Proportion recruited and characteristics (if } \\
\text { appropriate) of the recipient population for } \\
\text { the intervention. }\end{array}$ \\
\hline & 18 & $\begin{array}{l}\text { Primary and other outcome(s) of the } \\
\text { implementation strategy. }\end{array}$ & $\begin{array}{l}\text { Primary and other outcome(s) of the } \\
\text { intervention (if assessed). }\end{array}$ \\
\hline & 19 & Process outcomes related to the implementation & tegy mapped to the logic pathway. \\
\hline & 20 & $\begin{array}{l}\text { Resource use, costs, outcomes, and analysis for } \\
\text { the implementation strategy. }\end{array}$ & $\begin{array}{l}\text { Resource use, costs, outcomes, and analysis for } \\
\text { the intervention. }\end{array}$ \\
\hline & 21 & Representativeness and outcomes of subgroups, & Iding those recruited to specific research tasks. \\
\hline & 22 & $\begin{array}{l}\text { Fidelity to implementation strategy as planned } \\
\text { and adaptation to suit context and } \\
\text { preferences. }\end{array}$ & $\begin{array}{l}\text { Fidelity to delivering the core components of } \\
\text { intervention (where measured). }\end{array}$ \\
\hline & 23 & Contextual changes (if any) which may have affe & outcomes. \\
\hline & 24 & All important harms or unintended effects in eac & roup. \\
\hline
\end{tabular}


Table 1. Continued

\begin{tabular}{|c|c|c|c|}
\hline \multicolumn{2}{|c|}{$\begin{array}{l}\text { Report the } \\
\text { Following: }\end{array}$} & \multicolumn{2}{|c|}{$\begin{array}{l}\text { "Implementation strategy" refers to how the intervention was implemented. "Intervention" refers to } \\
\text { the healthcare or public health intervention that is being implemented. }\end{array}$} \\
\hline Checkli & & Implementation Strategy & Intervention \\
\hline \multirow[t]{2}{*}{ Discussion } & 25 & \multicolumn{2}{|c|}{$\begin{array}{l}\text { Summary of findings, strengths and limitations, comparisons with other studies, conclusions, and } \\
\text { implications. }\end{array}$} \\
\hline & 26 & \multicolumn{2}{|c|}{$\begin{array}{ll}\text { Discussion of policy, practice, and research } & \text { Discussion of policy, practice, and research } \\
\text { implications of the implementation strategy } & \text { implications of the intervention (specifically } \\
\text { (specifically including scalability). } & \text { including sustainability). }\end{array}$} \\
\hline General & 27 & \multicolumn{2}{|c|}{$\begin{array}{l}\text { Include statement(s) on regulatory approvals (including, as appropriate, ethical approval, confidential } \\
\text { use of routine data, governance approval), trial/study registration (availability of protocol), funding } \\
\text { and conflicts of interest. }\end{array}$} \\
\hline
\end{tabular}

* Reproduced with permission from Pinnock et al. ${ }^{13}$.

strategies for changing practice ${ }^{10}$, its potential is undermined by poor reporting of studies. Inconsistent terminology and taxonomy hinders indexing of implementation studies, making them hard to find when reviewing the literature. ${ }^{11}$ Lack of detail on what was done and how change was achieved reduces the utility for those wishing to replicate positive findings ${ }^{12}$, and limited descriptions of contexts make it difficult for readers to assess applicability to their primary care practice. The recent publication of the Standards for Reporting Implementation Studies (StaRI) provides a framework for comprehensive reporting of the results of implementation studies to promote further development of the field. ${ }^{13}$ This consensus effort was undertaken with the primary aim of providing authors with a checklist to improve and standardize reporting of implementation research, but there are messages for everyone seeking to change practice and improve quality of care. (see Table 1) The key concepts underlying StaRI (freely available via the EQUATOR website ${ }^{14}$ ) will influence the design and conduct of implementation research as well as inform the approach for achieving and measuring change in primary health care and population health improvement projects.

StaRI emphasizes the pivotal importance of context which may operate at many levels. For example, at an individual level, the approach to smoking cessation advice in a patient who perceives his cigarettes as something that are helping him cope with a domestic crisis is very different to the support we can offer the smoker who requests help on the first January to achieve a New Year's resolution. At an organizational level, the contextual characteristics of primary care influence the impact of implementation strategies. The relatively small organizations of primary care (compared with a large hospital) may make decisions to change easier to implement or, conversely, the geographic isolation of professionals working in small teams or centers scattered around the community may make it more difficult to address barriers to changing practice. Even within one health care system, primary care centers may be very diverse so that the strategies that will work in one practice may not be appropriate in another. StaRI highlights the need to monitor fidelity to the core content of both the intervention and implementation strategy, as well as report necessary adaptation to suit local organizational routines and professionals' and participants' preferences. Without a full description of fidelity to and adaptation of strategies and interventions, it is difficult to understand their impact on implementation and health outcomes and for readers to assess relevance to their particular situation.

StaRI distinguishes between the underutilized evidence-based intervention and the implementation strategy used to enhance adoption and sustainability in routine clinical care. ${ }^{15}$ For instance, to increase provision of an evidence-based health promotion intervention in a primary care center, apart from dissemination of guidelines, professional education, and training, we may consider strategies such as assessing "organizational readiness to change" to select participating centers; integration of information, communication, and decision support tools into the electronic health record; linkage with community organizations to extend reach; redistributing tasks among a multiprofessional team; 
and adjusting professional roles. ${ }^{16}$ This key distinction between the clinical intervention and the implementation strategy is crucial to conceptual thinking at the planning stage of quality improvement projects and informs the choice of outcomes measured as well as enabling clear reporting. The implication of these two different levels of actions and outcomes relevant to implementation may not immediately be clear to researchers used to working in a single level intervention model, but the companion explanation and elaboration document provides examples and additional detail. ${ }^{17}$

Fulfilling the reporting structures proposed by StaRI will be challenging for journals such as the Journal of the American Board of Family Medicine (JABFM), which will need to find innovative ways to meet the standards within the confines of their journal. It will require cooperation from the JABFM editorial staff on several fronts. First, they must instruct authors to use the format. Some authors will not be familiar with StaRI, and journals may need to direct them to resources such as the detailed explanation and elaboration document. ${ }^{17}$ StaRI promotes provision of all salient information in one document, so editors may need to maintain some flexibility in length constraints or encourage innovative ways to include detailed descriptions such as supplementary files or videos. Authors and readers too can play a critical role in the adoption of StaRI by providing feedback to JABFM editors on its utility and by encouraging others to adopt it as the standard format for communicating on these important issues. The choice is between accepting the unsatisfactory status quo or adopting strategies to improve reporting with a view to optimize the potential of implementation research to advance primary care.

To see this article online, please go to: http://jabfm.org/content/ 31/3/484.full.

\section{References}

1. Fischer LR, Solberg LI, Kottke TE. Quality improvement in primary care clinics. Jt Comm J Qual Improv 1998;24:361-70.

2. Grimshaw JM, Eccles MP, Lavis JN, Hill SJ, Squires JE. Knowledge translation of research findings. Implement Sci 2012;7:50.
3. McGlynn EA, Asch SM, Adams J, et al. The quality of health care delivered to adults in the United States. N Engl J Med 2003;348:2635-45.

4. Grol R. Successes and failures in the implementation of evidence-based guidelines for clinical practice. Med Care 2001;39:II46-54.

5. Eccles MP, Mittman BS. Welcome to implementation science. Implement Sci 2006;1:1.

6. Institute of Medicine (US) Committee on the future of primary care. Donaldson MS, Yordy KD, Lohr KN, et al., eds. Washington, DC: National Academies Press (US); 1996.

7. Helfrich CD, Weiner BJ, McKinney MM, Minasian L. Determinants of implementation effectiveness: adapting a framework for complex innovations. Med Care Res Rev 2007;64:279-303.

8. Mold JW, Lipman PD, Durako SJ. Coordinating centers and multi-practice-based research network (PBRN) research. J Am Board Fam Med 2012;25:577-81.

9. Ivers NM, Grimshaw JM. Reducing research waste with implementation laboratories. Lancet 2016;6:388:547-8.

10. Foy R, Eccles M, Grimshaw J. Why does primary care need more implementation research? Fam Pract 2001;18:353-5.

11. Pinnock H, Epiphaniou E, Pearce G, et al. Implementing supported self-management for asthma: a systematic review of implementation studies. BMC Medicine 2015;13:127.

12. Rycroft-Malone J, Burton CR. Is it time for standards for reporting on research about implementation? Worldviews Evid Based Nurs 2011;8:189-90.

13. Pinnock H, Barwick M, Carpenter C, et al. Standards for Reporting Implementation Studies (StaRI) statement. BMJ 2017;356:16795.

14. The EQUATOR Network: Enhancing the QUAlity and transparency of health research. Standards for Reporting Implementation Studies (StaRI) statement. Available from: http://www.equator-network. org/reporting-guidelines/stari-statement/ Accessed on March 7, 2017.

15. Curran GM, Bauer M, Mittman B, Pyne JM, Stetler C. Effectiveness implementation hybrid designs: combining elements of clinical effectiveness and implementation research to enhance public health impact. Med Care 2012;50:217-26.

16. Powell BJ, Waltz TJ, Chinman MJ, et al. A refined compilation of implementation strategies: results from the Expert Recommendations for Implementing Change (ERIC) project. Implement Sci 2015;10:21.

17. Pinnock H, Barwick M, Carpenter C, et al. Standards for Reporting Implementation Studies (StaRI): explanation and elaboration document. BMJ Open 2017;7:e013318. 